\title{
ESTILO EM PERSPECTIVA DISCURSIVA: UMA ANÁLISE DA REVISTA AEROLÂNDIA
}

\author{
Otávia Marques de FARIAS* \\ Lívia Márcia Tiba Rádis BAPTISTA*
}

- RESUMO: Neste trabalho, busca-se desenvolver uma noção de estilo a partir de uma perspectiva discursiva, utilizando-se, para isso, o arcabouço teórico da Análise do Discurso de linha francesa. Tomou-se como base Possenti (2008), que trabalha com a noção de repertório e de que todo enunciado tem estilo; Discini (2009), que defende a existência de duas dimensões para o estilo, a da totalidade (homogênea) e a da individualidade (heterogênea); Maingueneau (1983, 1984), que contribui com a ideia de polêmica como interincompreensão. Foram analisados os editoriais presentes nos quatro primeiros números da revista Aerolândia, análise por meio da qual se verificou como Outro principalmente a revista Aldeota, o que acabou por definir várias de suas escolhas ao relacionar forma e conteúdo e, consequentemente, foi fundamental na elaboração do estilo da publicação. Destacaram-se, dentre as escolhas, a construção da paródia, da ironia e da refutação. Percebeu-se ainda a opção por um senso de humor relacionado às regiões mais periféricas da cidade e a escolha de termos que remetem a esse universo de sentidos, além de ter-se constatado que, conforme se havia hipotetizado, a consideração da individualidade de estilo de cada enunciado pode, sim, ser cientificamente produtiva e não invalida a análise da totalidade.

- PALAVRAS-CHAVE: Estilo. Discurso. Polêmica discursiva.

\section{Introdução}

Neste artigo, propõe-se desenvolver uma noção de estilo consoante uma perspectiva discursiva. Vale observar que alguns autores, como, por exemplo, Possenti (2008) e Discini (2009), já realizaram uma aproximação dessa natureza, ou seja, teorizaram acerca do que seria ou poderia ser denominada uma Estilística discursiva. Com base nesses autores, o primeiro com o foco na relação entre singularidade e estilo à luz do discurso e a segunda orientada por uma abordagem semiótica-discursiva mais que propriamente voltada para o discurso nos termos de Análise do Discurso de linha francesa (doravante $\mathrm{AD}$ ), o que interessará aqui é propor que o estilo se fundamenta na polêmica como interincompreensão, fato

\footnotetext{
* Bolsista CAPES. Doutoranda em Linguística. UFC - Universidade Federal do Ceará. Fortaleza - CE - Brasil. 60020-181 - otaviamarques@gmail.com

** UFC - Universidade Federal do Ceará. Fortaleza - CE - Brasil. 60020-181 - liviarad@yahoo.com
} 
constitutivo de qualquer enunciado. Mais detalhes a respeito da referida relação de interincompreensão serão abordados posteriormente.

Para que se compreenda o que está proposto neste artigo, é necessário apresentar, antes, algumas considerações sobre o modo como o estilo vem sendo visto nas áreas que abordam questões de linguagem e seu uso, a saber, a Literatura e a Linguística. É o que será realizado no tópico a seguir. Feito isso, posteriormente, serão analisados editoriais das quatro primeiras edições da revista Aerolândia, periódico criado em abril de 2010, na cidade de Fortaleza, e que lida com questões relacionadas à cidade de forma muito peculiar, marcada pelo humor e pela irreverência, e mantendo um diálogo polêmico com outra publicação local, iniciada apenas dois meses antes, a revista Aldeota.

\section{Breve percurso sobre o estilo na Literatura e na Linguística}

Contradizendo o que poderia supor o senso comum, o conceito de estilo não é simples, contudo isso não significa que não haja definições de estilo elaboradas e operacionais. Ao contrário. E é esta, justamente, a questão: no âmbito dos estudos da linguagem, e estão sendo incluídas aí tanto Literatura quanto Linguística ${ }^{1}$, há uma profusão de conceitos de estilo, não conciliáveis entre si, propostos e exaustivamente trabalhados ao longo do tempo.

A referida profusão, então, acaba fazendo com que nenhuma pesquisa acerca do estilo, seja sobre que objeto for, possa prescindir de uma discussão prévia sobre a própria noção de estilo, com o propósito de organizar e esclarecer pressupostos, objetivos e métodos.

No presente artigo, trabalha-se com a ideia de que não é possível considerar o estilo sem levar em conta os aspectos histórico-sociais e ideológicos que, conforme se assume aqui, perpassam qualquer evento comunicativo. A perspectiva, portanto, é discursiva, porém supera a proposição advinda de momentos anteriores da AD, em que se concebia o sujeito da enunciação como completamente assujeitado a um lugar discursivo a partir do qual enunciava.

Para fins de elucidação de como o estilo está sendo concebido neste trabalho, torna-se necessário situar o ponto de vista discursivo com o qual se está lidando. Com esse propósito, é fundamental que se apresente um breve percurso acerca do estilo. Iniciar-se-á com as incursões da crítica literária no âmbito dos estudos estilísticos.

\footnotetext{
Os estudos literários (mais especificamente, de crítica literária) foram aqui incluídos por poderem ser considerados, para os objetivos deste trabalho, também estudos acerca da linguagem, na medida em que se voltam para a explicação de certos usos ou de certas formas específicas de utilizar a língua. Embora focalizando apenas a obra literária, não se poderia deixar de fora tal tradição, principalmente em virtude da importância teórica dos estudos acerca do estilo que engendrou.
} 
Possenti (2008) identifica três grandes vertentes principais nas quais se concentraram as análises literárias de estilo, a saber, a psicologizante, a sociologizante e a formalista. A primeira é, provavelmente, a mais importante, em virtude da grande influência que exerceu e exerce, até hoje, sobre o olhar de teóricos e de leigos no que concerne ao estilo. O nome ao qual se pode associar tal corrente é o de Spitzer (1974), que, como se pode supor, não foi o único pesquisador que se dedicou a essa abordagem, mas, certamente, foi o mais relevante e emblemático.

De acordo com Spitzer (1974), o estilo seria desvio de um uso considerado normal da língua, resultante de um estado psicológico alterado, ou, mais exatamente, a alteração das emoções normais do autor corresponderia a uma alteração do uso normal da língua por parte dele. Por meio da análise do estilo de uma obra, portanto, chegar-se-ia a uma compreensão acerca dos estados psíquicos do autor, de suas intenções, uma vez que o escritor, nessa condição alterada de espírito, buscaria expressar-se de modo intencional, ou seja, elaboraria modos não usuais de expressar seus estados mentais incomuns. Haveria, desse modo, intencionalidade por parte do autor e, o mais importante, a restrição da capacidade de se expressar com estilo, atribuída a citada aptidão somente àqueles que tivessem sido agraciados com uma espécie de dom: os gênios da literatura.

Já a abordagem sociologizante encontra em Auerbach (1971) seu principal representante. Para ele, a obra refletiria a ideologia de uma época, ou seja, tudo em uma obra literária (personagens, cenários, conflitos, desfecho) seria representação de certo contexto social, que tanto poderia ser apreendido por intermédio da produção de um autor quanto poderia ser utilizado para explicá-la. Aspectos individuais da autoria ficariam em segundo plano, e o estilo nada mais seria que o modo de os referidos aspectos sócio-ideológicos serem evocados para a construção da obra literária.

Há, por fim, a concepção formalista de estilo, voltada exclusivamente para a materialidade da obra. Desenvolvida em seus fundamentos pela Escola de Praga, essa vertente cria que o estilo advinha do uso de formas linguísticas incomuns, diferentes das usuais (desvios, portanto) e empregadas para gerar um efeito estético associado a um resultado expressivo reforçado ou multiplicado. Assim, a repetição de uma sequência sonora em um enunciado, por exemplo, serviria para multiplicar o efeito estilístico gerado pelo som em questão.

É válido, neste ponto, observar o que se considera, no presente estudo, adequado e inadequado em cada uma dessas concepções de estilo. A partir daí, começar-se-á a delinear a noção de estilo aqui sugerida.

A primeira vertente é problemática, principalmente em decorrência do fato de que confere importância demasiada à figura do autor. Nesse ponto de vista, 
o estilo decorre exclusivamente da capacidade e da inspiração deste. Exclui-se, dessa maneira, qualquer tipo de interpelação ideológica ou qualquer aspecto social que se imponha ou, ao menos, se insinue como decisivo sobre certo modo de escrever. Além disso, como já mostrado, considera-se que somente os textos literários, dotados de expressividade, podem apresentar estilo.

Ora, neste trabalho, diferentemente, e em conformidade com Possenti (2008), considera-se a figura do sujeito não como totalmente assujeitado a um lugar discursivo, ou seja, o sujeito-posição. Desse modo, o sujeito é visto como habilitado a fazer escolhas a partir das práticas discursivas em que se insere. Assim, diante dele, colocam-se opções, que se encontram na confluência entre as possibilidades da língua e as possibilidades de suas vinculações discursivoideológicas. Não se limita a isso o que consideramos aqui: com relação a quem pode se expressar através de uma linguagem dotada de estilo, compreende-se que todo e qualquer enunciado apresenta estilo, já que é o resultado das escolhas efetuadas pelo sujeito. Daí, pois, a ênfase na capacidade do sujeito em realizar escolhas, orientando-se por determinados fins que podem ser de distinta natureza discursivo-ideológica.

$\mathrm{Na}$ segunda concepção, a partir da ênfase dada às citadas condições de produção, acabam-se produzindo análises completamente voltadas para explicações baseadas em relações sociais, aspectos ideológicos, estereótipos etc. Essa maneira de conceber o estilo, no final das contas, resulta em estudos por demais amplos, que deixam de lado aspectos do estilo mais vinculados à materialidade da língua. Não observa, igualmente, o papel do sujeito e as escolhas que faz, postura adotada neste trabalho, conforme exposto em momento anterior.

Em contraposição, a terceira abordagem somente leva em conta os aspectos materiais, formais da língua. Repetição de sons, organização dos sintagmas, constituição mórfica das palavras são alguns dos pontos que merecem a atenção dessa vertente da crítica literária acerca do estilo. Mais uma vez, essa visão compreende estudos excessivamente limitados, que excluem aspectos estilísticos, como a atuação dos sujeitos e o âmbito discursivo, visto neste trabalho como constitutivo da linguagem.

Tanto na primeira concepção quanto na terceira advindas da Teoria da Literatura, encontramos a noção de estilo como desvio com relação a um uso considerado normal. Mas como saber se determinado uso foge ou não da normalidade linguística? Como mensurá-la? Indo adiante: seria possível falar em uso normal em oposição a um uso desviante? Nesta pesquisa, considera-se que não, já que não haveria como medir até que ponto algo pode ser considerado normal ou neutro em linguagem ou tampouco definir a partir de que momento seria atravessada essa fronteira da normalidade para se chegar ao espaço do desvio. 
Na segunda concepção, por sua vez, o que se percebe é que as análises realizadas dependem muito mais do conhecimento e da competência do pesquisador do que de um método bem construído e que possa ser aplicado a vários objetos diferentes. Por outro lado, é necessário reconhecer uma vantagem dessa abordagem: de algum modo, por realizar estudos baseados em aspectos sócio-históricos, acaba por incluir o que a AD denomina "condições de produção". Há, portanto, alguma aproximação dessa perspectiva com a adotada aqui, embora seja fundamental ressaltar que, na presente proposta, vai-se muito além da simples consideração das condições de produção, uma vez que se busca explicar o estilo a partir da noção de polêmica como interincompreensão e sem perder de vista o papel do sujeito nos aspectos estilísticos, dimensão excluída da segunda vertente trabalhada pela crítica literária.

Após a síntese das três principais vertentes de estudos a respeito do estilo oriundas do âmbito da Literatura, passar-se-á a um breve percurso acerca do estilo no âmbito da Linguística. Com esse intuito, cabe aqui mencionar a seguinte citação de Possenti (2008, p.249):

\begin{abstract}
Vimos que a noção de estilo é bastante confusa, havendo desta palavra numerosas definições (ver, por exemplo, Chociay, 1983, que comenta nada menos do que doze delas). [...] Entre a fluidez que se percebe nos tratamentos do estilo pelos críticos literários e a tentativa de estabelecer uma univocidade maior para este conceito, situam-se os linguistas, que tentam depreender noções um pouco mais severamente controláveis com base nas respectivas concepções de gramática (ou de língua).
\end{abstract}

A Linguística, como ciência preocupada com a exatidão conceitual e com o estabelecimento de métodos aplicáveis a objetos diversos, realizou as suas incursões no campo dos estudos sobre o estilo de maneira própria. Não se pode afirmar não ter sofrido influências da estilística literária, posto que, em certos momentos, recorreu a ela como referencial teórico inicial no qual baseou suas abordagens, ainda que refutando as teses propostas pela crítica literária. Adentrar-se-á agora o universo da estilística linguística, observando as teorizações de alguns linguistas representativos de concepções de estilo relevantes para esta pesquisa.

Conforme Possenti (2008), linguistas que trataram do estilo podem ser encaixados em duas vertentes: em primeiro lugar, aqueles que compreendem que, de um lado, está a gramática e, de outro, o estilo; em segundo lugar, os que consideram o estilo como um fato de língua. Segundo Possenti (2008, p.250), estes são um pouco mais adequados que aqueles, mas, no fim das contas, "caem no mesmo esquema de raciocínio", pois trabalham com a divisão em funções da linguagem e findam por enquadrar o estilo também fora da gramática/língua. 
Representativo da primeira vertente é Melo (1945 apud POSSENTI, 2008, p.250), que afirma: "A distinção entre língua e estilo se funda da clássica dicotomia estabelecida pelo grande Saussure - langue e parole." Para o autor, então, não só se mantém a noção de língua em oposição à fala, ou seja, sistema x uso, como também coloca o estilo como do âmbito da fala, encontrando-se, portanto, do lado caótico, assistemático e individual da língua. Em outras palavras: segundo essa vertente, não há estilo na língua.

A segunda vertente pode ser representada por dois autores. São eles: Charles Bally e Mattoso Câmara Jr., que, "[...] embora partam de pontos de vista um pouco diversos, acabam por produzir uma visão do estilo mais ou menos com os mesmos resultados." (POSSENTI, 2008, p.251). Vejamos como se posiciona cada um deles e o que propõem.

Bally (1951) produziu no âmbito do estruturalismo europeu. Em decorrência desse fato, sua teorização está marcada pelos ensinamentos de Saussure. Parte da ideia, portanto, de que a linguagem é expressão do pensamento. Não para, porém, por aí: afirma que expressar o pensamento é uma das funções da linguagem, mas não a única, uma vez que, a partir de uma deformação da realidade imposta pelo eu, serve a linguagem também para expressão de uma dimensão afetiva desse mesmo eu. Incluem-se na referida dimensão sentimentos, desejos, emoções, impulsos etc.

O principal problema encontrado na visão de Bally a respeito do estilo é que ela se baseia, primeiramente, na noção de que, como a afetividade pode ser expressa na língua em diferentes graus, seria possível pensar em uma linguagem neutra, ou seja, sem expressão afetiva e, portanto, sem estilo. Conforme explicado anteriormente, assume-se, neste trabalho, que não há linguagem sem estilo. Assim, a ausência do que Bally chamou de afetividade não significa ausência de estilo, pois não prescinde das escolhas que estamos considerando como base da constituição estilística da linguagem. Como todo enunciado pressupõe escolhas por parte do sujeito, não haverá, portanto, eventos comunicativos sem estilo.

Câmara Jr. (1953) parte de outro ponto, não lidando com a dicotomia língua x fala, mas partindo direto para a consideração das funções da linguagem como base para a sua estilística. Toma Bühler (1950) como referencial para as funções, postulando, dessa forma, que o estilo estaria ligado às funções de expressão, apelo e representação. Sua perspectiva acaba por chegar ao mesmo ponto que a de Bally (1951), na medida em que Câmara Jr. (1953) vê presença de estilo em enunciados com função de expressão ou apelo e ausência de estilo quando há a função de representação. Além disso, ainda de acordo com Possenti (2008, p.255), acerca da visão de Câmara Jr. sobre o papel do analista de estilo: 
Sua tarefa se triparte da seguinte maneira: a) caracterizar uma personalidade; b) isolar os traços do sistema lingüístico que não são propriamente coletivos e concorrem 'para uma como que língua individual', c) concatenar e interpretar dados expressivos.

Pode-se notar, a partir da citação acima, que Câmara Jr. (1953) sofre influências da corrente psicologizante da crítica literária. Advém daí sua preocupação com a personalidade do autor e com uma "língua individual". Mais uma vez, atribui-se ao autor demasiada importância, e aquele que faz uso da língua "com estilo" é visto como indivíduo que atua de forma totalmente intencional, agindo somente segundo a sua vontade de dizer.

Tal percurso só terá uma mudança de rumo significativa a partir de certos avanços conquistados com o estabelecimento da Sociolinguística. O mais relevante deles é ter-se firmado o conceito de língua como realidade intrinsecamente variável, ou seja, como tendo qualquer língua diversas variedades que a constituem. Devido a esse olhar, foi possível que se compreendesse que não há alguns usos que fazem parte da gramática e outros que são do universo do estilo, mas, na verdade, que todos os usos são variedades da língua e, desse modo, devem ser vistos como fazendo parte da gramática e sendo dotados de estilo simultaneamente. É possível falar nesses termos, porque, na Sociolinguística, há importantes teóricos que tratam da comunicação, percebendo nela que as escolhas feitas pelos usuários estariam de acordo com o seu repertório e que seriam direcionadas tanto pelo contexto quanto pelo propósito comunicativo, o que seria o caso de Gumperz (1968), Hymes (1972), Fishman (1979) e Lavandera (1984). No concernente à defesa de que o estilo está presente sempre, em qualquer ato comunicativo, pode-se citar Labov (1973).

Considerando o que foi apresentado até o momento, é possível ter um esboço do quadro acerca do estilo que queremos delinear aqui. Falta, ainda, especificar com que contribuições de Possenti (2008) e de Discini (2009) trabalharemos, além de expor de que maneira a polêmica como interincompreensão pode ser constitutiva do estilo. É o que será feito no seguinte tópico.

\section{A polêmica discursiva como base para a constituição do estilo}

Primeiramente, é necessário reforçar que a ideia de estilo ora defendida assume alguns aspectos da perspectiva de Possenti (2008) e de Discini (2009), embora difira de ambos em determinados pontos. O primeiro retira da Sociolinguística a noção de repertório e, baseando-se em Granger (1968), percebe a atuação do sujeito como trabalho. Essa perspectiva de Granger (1968) de trabalho relaciona-se ao seu modo de conceber a linguagem, a saber, como uma associação não ocasional entre formas e conteúdos. O que definiria tal associação seria, então, o trabalho 
do sujeito que, ao efetuar suas escolhas, vincularia uma forma a um conteúdo de modo particular ou singular, o que constituiria exatamente o estilo. É justamente tomando essa visão como fundamento que Possenti concebe o estilo. De acordo com Pereira (2005, p.187, grifo do autor):

\begin{abstract}
Possenti (1988) assume essa posição de Granger, que valoriza o individual, mas procura reforçar a base social e lingüística do estilo. Caracteriza o estilo como escolha, fruto do trabalho do sujeito na linguagem. Portanto, para Possenti, sempre há estilo, porque há o trabalho e a atividade social e histórica dos sujeitos com e sobre a linguagem. Para a existência do estilo, além do sujeito que faça escolhas, há a necessidade, ainda, de um repertório de recursos expressivos, de onde o sujeito fará suas escolhas, para conseguir os efeitos de sentido almejados. Este é o ponto de partida necessário para se poder pensar a questão do estilo, para Possenti: "a variabilidade dos recursos como constitutiva da língua."
\end{abstract}

Está-se considerando, aqui, o estilo exatamente nessa confluência entre o individual e o coletivo, entre a atuação do sujeito na linguagem e seu lugar social, que direciona o dizer para alguns lugares possíveis.

Pode-se, então, aproximar essa proposta de Possenti (2008) da de Discini (2009), embora, vale ressaltar, essa autora construa a sua definição de estilo de forma distinta. Para Discini (2009), o estilo se faz presente em todos os enunciados, não se podendo falar, portanto, em uso dotado de estilo e uso em que o estilo não se manifesta. Além disso, há ainda uma concepção da autora que será de grande validade para a presente pesquisa: o estilo se encontra no todo de um discurso, e é nessa totalidade que pode ser caracterizado de forma homogênea. Ao mesmo tempo, há as diferentes enunciações oriundas do discurso e, caso tomemos os diferentes enunciados resultantes delas, teremos não mais a mesma homogeneidade do discurso como um todo, mas nos colocaremos diante de uma realidade heterogênea. Nas palavras de Discini (2009, p.67, grifo do autor):

A totalidade de estilo é homogênea e heterogênea. O fato de estilo garante essa homogeneidade, já que pressupõe uma semelhança de procedimentos na construção do sentido que, por sua vez, constrói o ator da enunciação, efeito de individuação de uma totalidade. É heterogênea, pois supõe uma relação dialógica entre a grandeza inteira e discreta, o unus, com outras unidades integrais, num desdobramento do diálogo do discurso com as formações ideológicas de uma cultura. É do diálogo que falamos, ao pensar numa heterogeneidade constitutiva de um estilo, que se não mantém fechado em si mesmo, aprisionado nos próprios limites que o definem. Esta definição de limites, que aponta para o eu que fala por meio de uma totalidade, se faz exatamente pela relação com o não-limite, com o não-eu, com o outro. 
Assim, segundo a autora, os modos de produção de sentidos atualizados pelos atores da enunciação acabam por criar efeitos de individuação, ou seja, engendram compreensões acerca dos enunciados que apontam para a existência de características atribuíveis aos atores das enunciações. Simultaneamente, tais modos de produção de sentidos se mostram típicos não apenas de um ator específico, mas também definidores de toda prática discursiva, e é dessa maneira que o fato de estilo se apresenta homogêneo e heterogêneo a um só tempo. Vale ainda enfatizar que, de acordo com a pesquisadora, os discursos não se constituem estilisticamente de modo isolado. Seu estilo é definido na relação com os estilos de seus Outros, ao estabelecerem-se alianças, conflitos, neutralidade: diálogos, enfim. Com base nessa proposta teórica de Discini (2009), o estilo é compreendido como fundado no interdiscurso, sendo esta a principal contribuição da autora para este trabalho.

Considerar-se-á, então, o estilo da revista Aerolândia como uma totalidade, representada aqui por seus editoriais, a fim de demarcar os aspectos estilísticos dessa totalidade discursiva, consoante os objetivos deste artigo. Porém, salientamos que o que deixaremos de lado é a ideia da pesquisadora de que as individualidades, que resultam na heterogeneidade, devem ser desconsideradas. Os aspectos mais pontuais, que se realizam por meio das escolhas linguísticas mostradas nos textos (de que nos fala Possenti), serão, portanto, considerados ao lado da totalidade estilística que se constituirá ao longo da análise.

Tal análise da totalidade, articulada à da individualidade estilística, será realizada com base na noção de polêmica como interincompreensão, conforme já esclarecido em momento anterior deste trabalho. O conceito de polêmica como interincompreensão generalizada foi trabalhado por Maingueneau em duas de suas obras, a saber, Semantique de la polemique (MAINGUENEAU, 1983) e Gênese dos Discursos (MAINGUENEAU, 1984). Nesses livros, o autor trata das relações polêmicas existentes entre o discurso humanista devoto e o jansenista, ambos pertencentes ao âmbito do campo religioso. No caso analisado pelo autor, um dos discursos, o jansenista, constitui-se a partir do outro, mais precisamente, a partir da negação do simulacro do outro.

A polêmica, de acordo com Maingueneau $(1983,1984)$, seria a própria condição de existência dos discursos, já que cada um se estabelece a partir de sua relação com o(s) Outro(s). A característica mais forte dessa relação é exatamente a não compreensão mútua entre os discursos, que constroem simulacros daqueles com os quais se encontram em concorrência.

A não compreensão não é reconhecida dentro das leis que regulam um discurso, e o desconhecimento aí implicado também é constitutivo. Essa ausência de compreensão não reconhecida é necessária para marcar a diferença de um discurso com relação aos outros, formar sua identidade. 
Em outras palavras, significa que cada discurso se caracteriza por um sistema de restrições que determina não somente o que pode ser dito a partir dele, o que deve ser dito, mas também o que não pode ser enunciado, simplesmente por não fazer parte dos enunciados possíveis a partir da prática discursiva em questão. Essa impossibilidade de enunciar de modo diferente do pré-definido para um discurso tem implicações ainda na interação com enunciadores de outros. Isso porque, se não é possível enunciar de uma maneira determinada, pois certos sentidos não significam dentro de sua grade semântica, certamente também não será possível compreender o que diz um enunciador que enuncia das práticas discursivas na qual esses sentidos são os que devem ser enunciados.

A questão é que o enunciador não reconhece seu não entendimento. Interpreta, então, a enunciação do Outro com base nas regras de seu próprio discurso, resultando na chamada interincompreensão generalizada (MAINGUENEAU, 1984). De acordo com o autor:

Quando se considera o espaço discursivo como rede de interação semântica, ele define um processo de interincompreensão generalizada, a própria condição de possibilidade das diversas posições enunciativas. Para elas, não há dissociação entre o fato de enunciar em conformidade com as regras de sua própria formação discursiva e de "não compreender" o sentido dos enunciados do Outro; são duas facetas do mesmo fenômeno. No modelo, isso se manifesta no fato de que cada discurso é delimitado por uma grade semântica que, em um mesmo movimento, funda o desentendimento recíproco. (MAINGUENEAU, 1984, p.103).

Faz-se mister, entretanto, esclarecer que, neste trabalho, assim como em Farias (2008), ${ }^{2}$ é feito um deslocamento da noção inicial de polêmica discursiva como interincompreensão cunhada por Maingueneau (1983, 1984). O autor constrói, nas referidas obras, uma teoria da polêmica que se dá entre discursos que se constituem um a partir do outro, o que pressupõe a anterioridade de um, permitindo a assunção de seu Outro, que carrega em si aquele a partir do qual se constituiu, muitas vezes negando o discurso anterior. Por esse motivo é que um dos livros se chama Gênese dos discursos: exatamente por tratar do processo de constituição de um discurso a partir de outro(s) que preexistia(m).

O deslocamento realizado neste artigo se dá no sentido de que não se está lidando com o processo de constituição de discursos nem se está levando em consideração que discurso surgiu antes e permitiu o aparecimento de

Dissertação de mestrado intitulada "A polêmica como interincompreensão em artigos de opinião acerca do Estatuto da Igualdade Racial", orientada pela professora doutora Lívia M. T. Rádis Baptista, apresentada ao Programa de Pós-Graduação em Linguística da UFC. 
outro(s) com uma configuração diferente no mesmo campo. Esse deslocamento se justifica pelo fato de que, neste artigo, trabalha-se com a ideia de que a interincompreensão se estabelece entre discursos de um mesmo campo e que, para examiná-la, não é fundamental avaliar processos de formação de discursos. Um mesmo sema, "capital", por exemplo, aparece nos textos analisados com efeitos de sentido diversos, dependendo do posicionamento do enunciador. Mais do que isso, pode-se constatar que um enunciador que enuncia "capital" com um posicionamento " $\mathrm{x}$ ", ao entrar em contato com outro que enuncia com um posicionamento " $y$ ", continua traduzindo os enunciados de " $y$ " que contêm o mesmo sema como se fossem " $x$ ". Assim, tem-se um caso de interincompreensão passível de ser analisado sem que seja necessário estudar a gênese dos discursos envolvidos.

Além disso, é imperativo reforçar outro deslocamento que é feito no presente trabalho e que se relaciona ao mencionado no parágrafo anterior. Para Maingueneau (1983, 1984), a polêmica como interincompreensão é sempre e somente constitutiva, ou seja, está presente em todas as relações interdiscursivas. O que se faz aqui, contudo, pressupõe a possibilidade de uma interincompreensão mostrada ${ }^{3}$, também já defendida em Farias (2008). Assim, tornamos um conceito teórico em categoria operacional de análise, o que permite um estudo dos efeitos de sentido resultantes das relações entre determinados discursos, estudo este conduzido por meio de uma perspectiva verdadeiramente discursiva, mas que parte da materialidade do texto para ser realizado.

Portanto, essa interincompreensão mostrada se realiza de modo a deixar evidente o "diálogo" entre lugares discursivos diferentes. Sendo assim, a partir de um discurso determinado, em virtude de suas regras de restrição, além de não se poder/ter que enunciar de certa forma, também não se compreende aquilo que é enunciado a partir de outro discurso, senão fazendo uma tradução. Vale dizer que essa tradução estará necessariamente de acordo com suas próprias regras, já que é impossível conhecer e compreender as regras de funcionamento do Outro da mesma maneira que ele. Deste modo, as relações entre discursos se estabelecem fundamentadas em simulacros dos sentidos dos enunciados do Outro, resultantes da interincompreensão.

Segundo nossa proposta, tais simulacros podem ser evidenciados nos textos, deixando manifesto o jogo polêmico que as práticas discursivas constroem em suas inter-relações. Algumas estratégias linguístico-discursivas parecem se prestar, de modo especial, a cunhar ocorrências de interincompreensão mostrada.

O termo certamente remeterá à obra de Authier-Revuz. Contudo, apenas o "espírito" de nossa proposta é semelhante, não havendo a intenção de se trabalhar com as sistematizações da autora. 
A ironia ${ }^{4}$, a refutação ${ }^{5}$ e a paródia ${ }^{6}$ são as estratégias que escolhemos enfocar na análise da Aerolândia, pois parecem oferecer ao co-enunciador o simulacro do Outro de modo mais patente. Isso porque, no processo de constituição de enunciados em que essas estratégias são mobilizadas, o enunciador sempre lida com o discurso do Outro, apresentando-o a seu modo, para silenciá-lo e ressignificá-lo. Assim, por exemplo, partindo de uma perspectiva ainda sem o refinamento científico que se buscará em ponto posterior deste texto, podemos dizer que, com a ironia, pretende-se que os enunciados proferidos sejam atribuídos ao Outro, procurando-se, por meio de algum recurso (entoação, aspas etc.), evidenciar que o dito não pertence ao enunciador que o enunciou, mas está sendo negado por ele, que se encontra em conflito com o lugar discursivo do qual constitui o simulacro.

Desse modo, apenas para que a concepção de estilo fundado em uma interincompreensão mostrada fique clara aqui, anteciparemos um exemplo do corpus analisado. Trata-se de uma ocorrência de refutação, presente no editorial do primeiro número da Revista Aerolândia (2010a), em que se lê: "Sou editor-chefe da Aerolândia, mas não moro na Aerolândia. Nem pretendo". Ao lado do editorial, há uma parte do mapa da cidade de Fortaleza em que se destaca o bairro popular que dá nome ao periódico.

Inicialmente, é necessário esclarecer que refutação e negação não têm o mesmo sentido. Segundo Moeschler (apud Brandão, 1998), a negação é um dos marcadores textuais possíveis da refutação e, para explicar como esta funciona, Brandão recorre a autores como Ducrot e Barbault (1981) e Ducrot (1987). Em sua explanação, a autora conclui, em linhas gerais, que, para haver refutação, é necessária a existência de uma relação polêmica entre o enunciado que contém o marcador de negação e enunciados anteriores a ele, ou seja, a refutação se fundamenta no interdiscurso. Caso não haja a negação polêmica, estaremos diante de simples negação descritiva.

Tomando como base o exposto acima, concluímos que, para haver refutação, é necessária a interincompreensão, uma vez que o que é negado polemicamente por um discurso é o simulacro de seu Outro. Assim, partimos da relação interdiscursiva estabelecida pela revista Aerolândia com a revista Aldeota. No primeiro número desta, encontramos, na capa, parte do mapa de Fortaleza, enfocando o bairro da Aldeota e seus arredores. O bairro aparece marcado em laranja, e certas regiões dos arredores são vistas em vermelho. Na parte inferior esquerda, uma legenda que esclarece: em vermelho, temos a Aldeota; em rosa, "só quer ser Aldeota"

\footnotetext{
4 Para o conceito de ironia, ver Brait (1996) e Orlandi (1983). Esta será retomada mais adiante.

5 Para o conceito de refutação, ver Brandão (1998) e Farias (2008). Aquela será retomada mais adiante.

6 Para o conceito de paródia, ver Bakhtin (1981) e Sant'Anna (1985). Ambos serão retomados mais adiante.
} 
(ALDEOTA, 2010a). Além disso, podemos citar também a quarta edição da Aldeota em cujo editorial lemos: "[...] completamos o primeiro mês de vida com muita satisfação e, pelo retorno dado, satisfazendo bem aos aldeóticos e aos pretendentes ao bairro-sensação." (ALDEOTA, 2010d).

A refutação estabelecida no editorial da Aerolândia se constitui sobre o simulacro elaborado da revista Aldeota. Segundo esse simulacro, baseado em enunciados como os exemplificados acima, a Aldeota considera um valor positivo morar no bairro, algo que, inclusive, comporia um grupo social do qual muitos gostariam de fazer parte. Tudo isso, segundo a tradução operada pela Aerolândia, remeteria a efeitos de sentido não desejados, associados a posicionamentos ideológicos conflitantes com aqueles que atribui a si. A refutação em questão, então, se constrói sobre o simulacro elaborado como consequência da interincompreensão. Nesse ponto, entra o aspecto do estilo como escolha, defendido por Possenti (2008): haveria muitas maneiras de esse enunciador se posicionar contrariamente ao discurso Outro, com o qual estabelece relação de conflito. Dentre todas elas, o enunciador trabalhou no sentido de construir um enunciado refutativo, no qual associa forma e conteúdo negando o simulacro que faz do outro, ao mesmo tempo em que apresenta seu posicionamento, que se pretende mais popular, não elitista, e segundo o qual o bairro da Aerolândia funciona como um símbolo da cidade, algo que se parece querer valorizar em detrimento do status social de viver em uma área como a Aldeota. Assim, o que flagramos nesse caso de refutação é um conflito de valores e, além disso, os enunciados de um discurso, a partir da interincompreensão, sendo traduzidos por meio das regras do outro. Por fim, vale lembrar, de acordo com Discini (2009), que a heterogeneidade produzida pelos vários textos e enunciadores da revista compõe uma unidade maior, englobante das recorrências nas escolhas realizadas nos vários enunciados, que apontam para efeitos de sentido alinhados do ponto de vista discursivo.

Para compreendermos melhor essas escolhas relacionadas à interincompreensão e seus efeitos de sentido na revista Aerolândia, é necessário sabermos um pouco mais sobre ela e sobre o periódico que se apresenta como seu Outro. Na Aerolândia, encontramos um estilo que se constrói a partir da relação com o Outro, o que, conforme já se tem conhecimento, ocorre em qualquer discurso. No caso específico dessa revista, o Outro com o qual se estabelece a relação polêmica é, principalmente, de acordo com o que já antecipamos, a outra revista, criada antes e intitulada Aldeota. Os próprios nomes das publicações, por si sós, já nos dão pistas acerca do que diferenciará o estilo de uma do estilo da outra. Sabe-se serem Aldeota e Aerolândia dois bairros da cidade de Fortaleza. Sabe-se também ser aquele o bairro mais emblemático da alta sociedade fortalezense, enquanto este é bairro periférico 
e dos mais pobres. Como, então, se estabelece a relação interdiscursiva entre as duas revistas? Vale a pena considerar mais algumas informações sobre elas, para começarmos a responder a essa pergunta.

A revista Aldeota teve seu primeiro número publicado em fevereiro de 2010. Circulou de duas maneiras: por meio da internet, com cada edição sendo disponibilizada integralmente em sites de compartilhamento de dados, e também de forma impressa. A versão impressa era feita com patrocínio de verba pública e, por isso, foi distribuída gratuitamente àqueles que se tornaram assinantes. Desde que passou a circular nos meios cultos e alternativos de Fortaleza, a Aldeota chamou bastante atenção, tanto pela apresentação gráfica, muito moderna e bem cuidada, quanto pela maneira como os temas relacionados à cidade eram abordados. Na revista, ao mesmo tempo em que se percebe uma valorização do local, há também a tentativa de colocar Fortaleza em um contexto nacional e, até mesmo, mundial com relação aos temas trabalhados.

A revista Aerolândia, por sua vez, não circulou em versão impressa. Todos os seus números, iniciados em abril de 2010, foram disponibilizados pela internet. $\mathrm{Na}$ primeira edição, já ficou muito claro o jogo de sentidos que ela pretendia fazer com a outra, sua antecessora. O tratamento gráfico muitíssimo parecido (incluindo-se, aí, o uso das cores, a disposição das informações e imagens nas páginas, as fontes utilizadas), os temas tratados, a organização feita integralmente com textos de colaboradores, tudo remeteu intencionalmente à Aldeota. Apesar disso, não foi difícil perceber que havia também muitas diferenças. Como afirmado, o título já dá a dica. Na revista Aerolândia, não são encontrados colaboradores que assinam suas colunas e cujos nomes funcionam, logo de início, como argumentos de autoridade (o que ocorre na Aldeota). Na Aerolândia, só nos deparamos com pseudônimos como Deusdete Odara, Kalanbowski Simão Pontes e Damião Dachenberg, entre outros. Os textos são bem-humorados, assim como os da Aldeota, porém não com um bom-humor que busca o refinamento para mostrar que em Fortaleza também há boas maneiras. A Aerolândia traz à tona o bom-humor com assuntos populares, direcionados a uma camada da população que não tenta se inserir em contextos mais amplos, mas ri das coisas da terra, faz galhofa com a própria pieguice e com a da periferia.

Desse modo, a Aerolândia se constitui tendo a Aldeota como Outro: ao mesmo tempo em que se aproveita de suas características, nega-as ao efetuar certas escolhas que refutam a tentativa de fazer da cidade algo refinado e cosmopolita. É como se a Aerolândia pretendesse marcar sempre que a cidade e seu povo não são assim e buscasse mostrar o real, salientando, a todo o momento, inclusive, a rudeza e as características mais próprias do cotidiano do humor local.

Todas essas questões estilísticas serão mais bem explicitadas e abordadas no tópico a seguir, destinado à análise. 


\section{O estilo nos editoriais da revista Aerolândia}

Observe-se o editorial do primeiro número da revista Aerolândia (2010a):

Boa tarde, leitores(as). Me chamo Carlos McGaren. Sou editor-chefe da REVISTA AEROLÂNDIA, mas não moro na Aerolândia. Nem pretendo. Nossa publicação, noviça no mercado editorial, reúne um espectro heterodoxo de colaboradores e amplíssimo leque de profissionais dedicados à danação ininterrupta e à profanação dos índices de civilidade.

Não se sobressaltem excessivamente se encontrarem circulando nesta FORTALEZA uma assemelhada revista. Em quase tudo, a supracitada vem tentando nos arremedar: no fino trato gráfico, na exigüidade de qualquer modéstia e, via de regra, na maneira algo cínica e desvairada de se portar virtualmente. Entretanto, faltam-lhe graça e, sim, bastante inteligência. Trata-se de duplo falso, um reflexo pardacento de nossa jovial empreitada.

Não lhes rogamos que não dediquem qualquer fração de tempo à leitura daquele pasquim, cujo nome exalta a fauna e a flora intestinal de uma região decadente da cidade. O que nos cabe agora é convidá-los para a leitura infinitamente mais prazenteira de AERO. Boa sorte.

Inicialmente, é válido lembrar os ensinamentos de Granger (1968), assumidos por Possenti (2008) acerca de como se constitui o estilo: trata-se de uma associação entre forma e conteúdo. Essa associação, por depender das escolhas realizadas pelo sujeito dentro de seu universo de possibilidades, é que finda por resultar no estilo. Pensando dessa maneira, entende-se que tudo o que faz parte do texto anterior deve ser visto como mais um passo no estabelecimento de um estilo.

Assim, por exemplo, tem-se, logo no início do editorial da primeira edição, uma referência ao nome da revista, seguida do esclarecimento de que seu editor-chefe não mora no bairro da Aerolândia e nem tem a intenção de fazêlo. Esse trecho foi analisado, em linhas gerais, anteriormente e, a partir dele, percebemos que vai se delineando desde o começo, conforme já sugerido, a noção de que Aerolândia é muito mais uma referência a certo universo de sentidos do que qualquer outra coisa. Torna-se necessário reforçar, a partir disso, que haveria várias outras maneiras de se remeter a tal conteúdo. A maneira escolhida pelo sujeito, porém, foi justamente afirmar que nem vive nem pretende viver no bairro que dá nome ao periódico. O fato de se ter optado especificamente por essa relação entre forma e conteúdo, mais que mostrar quem o sujeito é, o constrói diante do leitor da revista. Desse modo, fica claro que o estilo não é a simples expressão do sujeito, mas condição de existência que o funda. E isso vale não apenas para o trecho destacado, mas, evidentemente, para o texto como um todo. 
Outro ponto a ser ressaltado é a referência ao "[...] espectro heterodoxo de colaboradores e amplíssimo leque de profissionais dedicados à danação ininterrupta e à profanação dos índices de civilidade." (AEROLÂNDIA, 2010a). $\mathrm{Na}$ verdade, nunca se tomou conhecimento de quem seriam, na vida real, os tais colaboradores e profissionais citados no trecho. Levando-se em conta apenas os pseudônimos utilizados, perceber-se-á que o leque não é tão amplo assim, já que um número bastante restrito de personagens é mencionado. Ao se observar os textos assinados por eles no corpo da revista, é possível, sim, notar a heterogeneidade de personagens (fato que remete à ideia de Discini (2009) acerca da totalidade homogênea e da unidade heterogênea), o que nos leva a supor que o editor-chefe considera importante a existência de colaboradores com contribuições variadas (ou, dito em outros termos, colaboradores com estilos diferentes entre si). O que realmente importa é que já podemos entrever algo que será explicitado no parágrafo seguinte: a definição do Outro da revista Aerolândia como sendo a revista Aldeota. Aparentemente, então, a Aerolândia entende a recorrência dos mesmos autores nas edições da Aldeota como algo negativo, algo que evoca efeitos de sentido (como um certo ar de elegância elitista e exclusivista), valores sócio-ideológicos que ela busca contestar?. Esse fato se comprova na medida em que se sucedem os números da Aerolândia e se vê a rotatividade dos personagens-autores, alguns sumindo em certas edições, outros surgindo, ainda outros se mantendo presentes com mais frequência etc.

A ideia que vem logo em seguida, de que esses profissionais e colaboradores se dedicam "à danação ininterrupta e à profanação dos índices de civilidade" (AEROLÂNDIA, 2010a), é também uma forma de se contrapor ao seu Outro. Mais que isso: é um exemplo de relação polêmica, uma vez que figura como uma crítica à forma de se apresentar da Aldeota, que busca sempre ressaltar as credenciais de seus autores com informações, ao mesmo tempo, legitimadoras e elaboradas de forma bem-humorada. O que a Aldeota entende como uma forma de legitimar e elevar seus colaboradores, a Aerolândia, contudo, traduz como manutenção dos índices de civilidade, vistos, então, como algo negativo, a ser excluído. E, segundo a Aerolândia, profanar tais índices é o que seus colaboradores fazem.

\footnotetext{
Exemplificamos alguns enunciados presentes em editoriais da Aldeota que apontam para o universo de sentidos rejeitados pela Aerolândia e funcionam como base para a elaboração do simulacro daquela elaborado por esta: "O desejo de um tempo realmente novo, mas com tudo de bom que o passado nos reconta a cada dia é o princípio que domina nosso trabalho aqui, da primeira à última página. Vamos falar de vida e do bem-viver, prazeres da carne, do bolso, da mente e do espírito." (ALDEOTA, 2010a); "No entanto, não estamos aqui para desafiar o equilíbrio espiritual de ninguém e, fora do tempo, retornamos ao carnaval para mostrar que a arte de ser feliz pode muito bem ser constante. A leitura passa por diferentes tipos de novidades. Da wishlist da itgirl que, sim, também aprecia os cheap \& chic, ao novo emprego que, nunca, pode ser desconsiderado." (ALDEOTA, 2010b); "Aproveite a abundância da luz solar e se deleite na praia com a companhia leve e agradável do nosso terceiro número. No mais, vale se abanar ao terminar a última página." (ALDEOTA, 2010c); "Esta edição pretende seguir o mesmo rumo, apresentando para a ALDEOTA um de seus nobres representantes em uma conversa aristocrática e despretensiosa, como o próprio Barão." (ALDEOTA, 2010d).
} 
Nos parágrafos seguintes, prossegue a construção do simulacro do Outro através da interincompreensão e, consequentemente, da construção do estilo e, de forma simultânea, do sujeito desse estilo. De forma curiosa, apresenta-se a ideia de que outra revista vem tentando "arremedar" a Aerolândia. Mas como essa imitação seria possível se o editorial em questão é justamente de seu primeiro número? Tem-se aí uma brincadeira feita pelo sujeito. Primeiramente, com o termo "arremedar", tão próprio da gente de Fortaleza e que gera certo efeito de estilo. Em segundo lugar, o fato de que "arremedar" não é visto, dentro do discurso da Aerolândia, como um sema positivo. Atribui-se, a partir disso, a ação de imitar o Outro, quase como no gesto infantil de sempre afirmar que o mal-feito é obra de outra pessoa. Os que acompanhavam a revista Aldeota e passariam a acompanhar a Aerolândia, certamente, saberiam tratar-se desse jogo de "Não fui eu!", muito mais uma brincadeira da Aerolândia que, com ele, assumiu-se culpada pela paródia que iniciava naquele momento.

Aqui, considerando que estamos falando em paródia, é necessário refletir um pouco sobre ela como um fato estilístico fundado na interincompreensão. Segundo Bakhtin (1981), parodiar é criar o duplo "destronante", o mesmo mundo às avessas. Já Sant'Anna (1985), refere-se à paródia, entre outras coisas, como "espelho invertido", "deformação", "caráter contestador", "tomada de consciência crítica". Além dos citados, muitos outros autores trataram da paródia, cada um com um enfoque particular. É possível, entretanto, observar dois aspectos recorrentes nos vários teóricos: à paródia associam-se sempre as noções de alteração dos sentidos originais e de comicidade. É interessante, tomando esses aspectos, destacar a recorrência da ideia de mudança no sentido. Essa mudança, do ponto de vista discursivo, nada mais é que a tradução operada pelo Mesmo sobre o Outro, ou seja, a paródia se baseia na interincompreensão, no fato de que um discurso " $\mathrm{x}$ ", por não ter como compreender o discurso " $\mathrm{y}$ ", o traduzirá conforme suas próprias regras.

Desse modo, podemos afirmar que, na Aerolândia, há paródia em dois níveis: global e individual. Quanto ao no nível global, da unidade (remetendo a Discini (2009), a revista em si funciona como uma paródia da Aldeota e, como toda paródia, não é apenas destruição, o que significa que há o conflito, a negação de valores sócio-ideológicos traduzidos da Aldeota, mas há também a apropriação de características que demonstram certa identidade, ou seja, que há algo para ser renovado em vez de destruído (identidade que, inclusive, está expressa no primeiro editorial lido e que será retomada adiante). Já no nível individual, da heterogeneidade, a Aerolândia se aproveita de capas, personagens, colunas etc., presentes na Aldeota, para construir simulacros do Outro, negá-los e, nesse encontro entre semelhança e diferença, deixar entrever que valores sócioideológicos adota. 
Vale, ainda, observar mais alguns exemplos de interincompreensão presentes no editorial, que sustentam o aspecto de paródia bem-humorada atribuído à revista. Iniciemos por aquilo em que a Aerolândia afirma haver arremedo, ou seja, em que as duas revistas são semelhantes. A falta de modéstia é um dos aspectos citados. Compreende-se, com isso, que a Aerolândia considera a empreitada da Aldeota - ser uma revista de cultura e informação com ares de elegância e modernidade, em uma cidade provinciana, como "não modesta". O que a Aldeota deve ver como ousadia, a Aerolândia, por sua vez, traduz como falta de modéstia e afirma também ter tal característica. O mais interessante, aqui, é que a falta de modéstia que a Aerolândia atribui a si parece significar algo um pouco diferente dentro do Mesmo: parece ser a falta de modéstia típica dos que elogiam a si próprios. Não é difícil comprovar essa ideia, já que, logo em seguida, lemos no editorial que, à Aldeota, "[...] faltam-lhe graça e, sim, bastante inteligência. Trata-se de duplo falso, um reflexo pardacento de nossa jovial empreitada." (AEROLÂNDIA, 2010a). O que, na Aldeota, é colocado como bem-humorado e inteligente é traduzido pela Aerolândia como sem graça e sem inteligência. Essa diferente forma de compreender a falta de modéstia quando associada a si, pela Aerolândia, e quando associada à Aldeota, justifica-se pelo simulacro dos valores sócio-ideológicos que aquela atribui a esta e com os quais não considera estar em conjunção.

Mais um exemplo de interincompreensão pode ser visto no parágrafo seguinte, em que a revista Aldeota em si é traduzida, simplesmente, como "pasquim", epíteto nada elogioso atribuído a publicações de baixa qualidade. Curiosa também é a maneira de remeter ao nome da revista que estabelece como Outro: "[...] cujo nome exalta a fauna e a flora intestinal de uma região decadente da cidade." (AEROLÂNDIA, 2010a). A "fauna e a flora intestinal" figuram como a maneira da Aerolândia de traduzir algo que a Aldeota vê como positivo, a saber, os habitantes do bairro e o que dele advém. A revista Aldeota, ao escolher esse nome, desejou remeter, ao mesmo tempo, ao bairro, representativo da classe alta da cidade, e ao fato de que Fortaleza tem ares provincianos, ainda é uma pequena aldeia, uma aldeota. A Aerolândia, por sua vez, traduz Aldeota como "região decadente da cidade". Tudo isso aponta para o fato de que ambas enunciam a partir de lugares discursivos diferentes, ou seja, as práticas discursivas das quais elas são materialidade se sustentam na incompreensão mútua constitutiva, mas, mais que isso, especialmente a Aerolândia, foco de nosso estudo, cria formas de evidenciar esse Outro dentro de si, essa identidade parte aproveitada, parte negada. E o que seria, assim, esse processo de selecionar o que se quer como valor e o que não se quer, transformados em discurso que associa forma e conteúdo, senão estilo?

Em outras palavras, o que parece mais interessante nisso tudo é que, apesar de constituir a Aldeota como Outro e, nesse primeiro editorial, criticar a antecessora, a Aerolândia, na verdade, cria a relação polêmica muito mais para estabelecer 
seu lugar, ou seja, para demarcar seu estilo. Exatamente por isso, mantém muito da Aldeota, conforme já comentado anteriormente. As críticas, então, figuram como uma espécie de brincadeira que faz parte da grande paródia que é a revista Aerolândia. Indo além, é possível dizer que esse falar mal brincalhão está na base do próprio estilo que se constrói na totalidade do periódico e busca refletir uma característica do espírito bem-humorado do cearense: falar mal de quem se gosta e, mesmo assim, continuar tudo bem.

Vale a pena, ainda, fazer mais um comentário: o nome do editor-chefe, McGaren, é o de um dos inimigos do herói infantil japonês da década de noventa, Jaspion. Há, no primeiro número, algo que se repetirá em todos os outros: o editorchefe será sempre algum personagem curioso e, assim, nunca se terá uma autoria assumida. Não há como negar ser esse traço uma importante característica do estilo da Aerolândia, pois, além do aspecto cômico de se ter um personagem da série Jaspion como editor, há também a ausência de uma figura a quem relacionar a publicação, de alguém que possa ser responsabilizado pelo que se diz nela. Introduz-se, dessa maneira, a noção de que a não responsabilidade pelo dito será um aspecto do estilo da revista.

Passar-se-á ao editorial do exemplar de número 2:

Olá, mundiça generalizada.

Novamente, nós, da REVISTA AEROLÂNDIA, outorgamos o direito à leitura enviesada dos rincões da alma empenada desta região de Fortaleza, que fez os seus 284 anos na terça derradeira e, para comemorar, passou o trator no BECO DA POEIRA um dia antes. Por nosso turno, damos viva à cidade estampando em nossa capa os dejetos que vêm dos bairros nobres para o nosso quintal através do canal do Lagamar. Foto arrebatadora.

Enfim, mais um número. Estou apenas de passagem neste conselho editorial composto por figuras ilustres. Aceitei o convite para lhes escrever porque acredito no poder encantatório das palavras. Sério. Não é porque exerço a profissão que exerço (foder mulheres adoidado) que vou descuidar da cultura, da leitura, da reflexão, da força animada (no sentido 'hegeliano' e não no 'kantiano') que imprime o conhecimento às mentes fertilizadas com creme Neutrox.

Eu sou bem dotado em todos os sentidos, acreditem.

Boa leitura desta nova AERO. (AEROLÂNDIA, 2010b).

Considerando que muito já foi dito acerca da constituição do estilo na revista Aerolândia, de agora em diante, apenas alguns pontos de cada editorial serão destacados. Inicialmente, é necessário esclarecer que o texto acima é assinado por "Kid Bengala, o Bem Dotado. Editor de plantão". Prossegue-se, então, no propósito de negar a autoria e manter o tom humorístico da publicação. A novidade que se 
constitui, a partir desse número, é que cada editorial trará alguns aspectos que procuram reproduzir o estilo reconhecido como sendo do personagem evocado como editor. Ter-se-á, portanto, um estilo forjado dentro do estilo da revista. No caso de Kid Bengala, figura cômica do imaginário do sexo em nosso país, isso aparece, principalmente, no segundo parágrafo do editorial.

Outro aspecto que compõe o estilo da Aerolândia como totalidade e que está presente no editorial em questão é a ironia, que identificamos em trechos como: "[...] Fortaleza, que fez os seus 284 anos na terça derradeira e, para comemorar, passou o trator no BECO DA POEIRA ${ }^{8}$ um dia antes." e "Por nosso turno, damos viva à cidade estampando em nossa capa os dejetos que vêm dos bairros nobres para o nosso quintal através do canal do Lagamar." (AEROLÂNDIA, 2010b).

É válido destacar que, nesses casos, não temos uma referência tão direta à revista Aldeota. Na verdade, a ironia se constitui sobre um universo de sentidos, sobre aspectos sociais e ideológicos que, do ponto de vista da Aerolândia, parecem incluir a Aldeota, mas não se restringem a ela. Trata-se de uma espécie de discurso elitista, que se caracteriza, principalmente, por estabelecer forte distanciamento com relação a problemas e causas sociais, além de balizar seus temas e efeitos de sentido em questões do cotidiano das classes abastadas. Esse seria, então, um dos Outros mais relevantes dos discursos que ganham materialidade na revista Aerolândia, muitas vezes negado discursivamente por meio da negação à Aldeota.

A ironia que, segundo Orlandi (1983), é um tipo de discurso, uma prática de linguagem contextualmente situada, não pode ser vista como desvio ou sentido adicional: trata-se de um sentido diferente, marcado pela antecipação que o enunciador faz do mundo estabilizado de seu co-enunciador, engendrando inversão ou, até mesmo, rompimento.

No simulacro desse discurso negado pela Aerolândia, caberia, de fato, comemorar o fim do Beco da Poeira conforme a população mais pobre do município conhecia e também dar vivas a uma cidade que joga os dejetos da parte nobre na parte pobre. Tais valores são atribuídos por antecipação ao discurso Outro, ou seja, não se espera que isso seja dito, apenas se considera ser dizível a partir do discurso sobre o qual se constrói o simulacro.

Podemos dizer, portanto, que a ironia é um modo de trabalhar sobre a linguagem bastante recorrente na revista e, como uma de suas estratégias linguístico-discursivas mais utilizadas, marca o estilo do periódico.

\footnotetext{
O Beco da Poeira foi, durante muitos anos, o mais popular aglomerado comercial do Centro de Fortaleza. Tratava-se, na verdade, de um conjunto de boxes labirinticamente dispostos e encravados em um dos quarteirões de maior fluxo no bairro do Centro. Acabou também se tornando, para as pessoas da cidade, um ponto de referência, algumas vezes pelos baixos preços, outras, mais bem-humoradas, pela breguice que se costumava associar ao lugar. Foi desalojado e posto abaixo em virtude das obras para construção do metrô de Fortaleza.
} 
No terceiro editorial, lê-se:

Qualquer brasileiro, alfabetizado ou não, tem ciência de pelo menos uma coisa nesta vida: mais que o Pau Brasil, Tiradentes, a seleção de futebol do Brasil e Lula, é a bunda, e não eles, que nos une a todos.

Dito isso, passo adiante. Nesta semana, nossa revista enfrentou dificuldades as mais variadas. Filtradas, elas se concentram principalmente na falta de dinheiro. E o que minha fartura de nádegas, o que esta camada de pré-sal particular, esta colônia iridescente de estrias e celulites tem a ver com isso?

Tudo.

Além de escrever, fui convidada para, numa série de shows privados, destinados a comover profundamente personagens-chave cuja riqueza extrema pode nos auxiliar, angariar fundos a este empreendimento. Aceitei o convite por dois motivos: primeiro, acredito na sinceridade dos meninos e meninas que fazem a Aerolândia (Marquim, Deusimar, Ruilivínio, Francis, Eribaldo, Damião, Marlenne e Deusdete são provas disso). Segundo: somente agora vi que a bunda pode assumir contornos mais vivazes na cultura nacional. E sinto isso de um modo especial, visto que dependo desse playground de adultos para viver.

Sendo assim, abraço a causa. Celebro o descaramento e a lubricidade da equipe que, em vez de Che Guevara, um mito idiota e politicamente irresponsável, festeja a bunda, ícone que guarda, em dois hemisférios bem separados, segredos os mais inverossímeis. (AEROLÂNDIA, 2010c).

Assinado por "Rita Cadillac, editora chefe (e lady) de plantão", o texto constrói uma imagem interessante, que será marca da totalidade do estilo da revista. No caso do terceiro editorial, a imagem é construída a partir da oposição entre a bunda e Che Guevara como possíveis ícones a serem celebrados. A equipe que compõe a Aerolândia, representada pelos personagens citados pelo sujeito, opta por festejar a bunda, entendida como "ícone que guarda, em dois hemisférios bem separados, segredos os mais inverossímeis" e desabona Che Guevara, idolatrado por muitos, traduzindo-o, simplesmente, como "mito idiota e politicamente irresponsável" (AEROLÂNDIA, 2010c). Marca, desse modo, um posicionamento, esclarecendo de que forma interpreta a figura de Che Guevara e também lidando com o sexo e a figura feminina de maneira irreverente e explícita. Essa maneira de lidar com o sexo pode ser percebida em vários outros textos presentes nas edições da publicação.

Além disso, é de se salientar que, em Fortaleza, foi inaugurado um Centro Urbano de Cultura, Arte e Esporte (CUCA) chamado Che Guevara, em setembro de 2009. O leitor, portanto, encontra-se diante de uma referência à homenagem feita pela prefeitura municipal a uma personalidade que a revista Aerolândia, conforme já se disse, não traduz de forma positiva. 
Nesse caso, faz-se necessário observar mais uma ocorrência de refutação, uma das estratégias linguístico-discursivas que constituem o estilo da revista Aerolândia. Aqui, a refutação não se encontra em sua estrutura mais direta, não havendo, por exemplo, a palavra não como marca de negação. Mesmo assim, identificamos refutação em " [...] equipe que, em vez de Che Guevara, um mito idiota e politicamente irresponsável, festeja a bunda [...]" (AEROLÂNDIA, 2010c). Na verdade, consideramos que estamos diante de um enunciado que poderia ser estruturalmente reformulado em "Não festejamos Che Guevara, um mito idiota e politicamente irresponsável, festejamos a bunda". O discurso que se institui aí como Outro é o da autoridade instituída, identificada como a prefeitura de Fortaleza, que prestou homenagem, conforme já explicado, à figura histórica citada.

Mais uma vez, constrói-se um simulacro desse Outro, que parece, inclusive, adquirir aqui as mesmas características do mito: "idiota e politicamente irresponsável". Nesse ponto, a Aerolândia marca seu posicionamento de forma subversiva, quiçá protestadora. Toma como símbolo a ser festejado a bunda, sarcasticamente percebida como símbolo dos mais importantes na cultura nacional. Ou seja: a Aerolândia não tem como único Outro a Aldeota. Na verdade, pretende, por meio do uso de certas estratégias, sempre construindo simulacros (como não poderia deixar de ser), insurgir-se contra certa ordem estabelecida, que tem como símbolo a Aldeota, mas não se limita a ela.

Observe-se, agora, o editorial da edição de número quatro, assinada por "HAAAAAAAAAJA CORAÇÃO, AMIGO! Galvão Bueno - editor de plantão, narrando o fim desta publicação":

Acorda, Brasil!

Prepare seu coração. Chegou a hora de falar a milhões de leitores mundo inteiro que a nossa Aerolândia está terminando. Aquilo que parecia bom, que parecia eterno, que parecia a melhor coisa de que já se ouvira falar encontrou termo, fim, fecho, final. Para narrar essa venturosa etapa, essa empreitada anônima, cheia de animosidades animadas, esse experimento manobrado por mãos cavilosas, fui convidado a escrever lhes.

Eu, Galvão Ernesto Bueno, parti ainda ontem de Milão em vôo fretado e, após vencer o que pareciam vestígios da nuvem de poeira expelida pelo vulcão de nome impronunciável, saltei. Estava na altura da Passarela, a mesma que viu desfilarem as meninas mais cajuzinhos desta bela Fortaleza. Sobrevivi à queda amortecido por um colchão infinito de aguapés. Eles coalhavam o espelho do Lagamar. Ali, vislumbrei um rio que traz dejetos da área rica e os despeja na pobre sem pedir licença.

Voltando. Agora, em definitivo. Agora para falar com emoção. A grandiosa equipe da Revista Aerolândia agradece cada minuto, cada 
segundo, cada fração de tempo despendida na leitura de nossas páginas, desenhadas com sêmen, suor e cerveja. E se surpreende: como uma iniciativa espantosamente falta de criatividade logrou bolinar as mentes e corações de tantos e tantas? Nem mesmo eu, que gotejo experiência, encontro resposta.

Agora é a hora. A hora do show da despedida. Deusimar, Ruilivínio, Kalanbowski, Francis, Damião, Deusdete, Marcílio, Jason Felix, Eribaldo, Marlenne e, finalmente, o Marquim, novo titã da imprensa local, já bastante saturada de figuras anódinas, musculares, hipertrofiadas - essa gente toda diz: foi bom enquanto durou, negrada.

A gente vai pra casa. Sem chances de retorno. Entretanto, deixamos aqui a mensagem: mesmo separados, nossos corações continuarão sendo imensos, bem maiores que a BR-116.

Adeus. (AEROLÂNDIA, 2010d).

Primeiramente, observamos que, dos quatro editoriais aqui analisados, é neste que o efeito pretendido pela simulação do estilo do personagem tomado como editor, dentro do estilo da revista, é o mais perceptível. Qualquer pessoa que já tenha acompanhado as narrações de Galvão Bueno perceberá vários bordões utilizados por ele, além da tendência ao uso de imagens exageradas, comuns na maneira como o narrador relaciona forma e conteúdo.

Retomamos, então, a paródia, já que todo o quarto editorial se constrói como uma, repetindo, na parte, a característica presente no todo. O final da revista (que, na verdade, não ocorre no momento anunciado, pois há ao menos mais nove exemplares depois da quarta edição) é divulgado por meio da maneira como a Aerolândia compreende uma narração de Galvão Bueno. Algo no meio do editorial, porém, chama a atenção. O sujeito que forja o estilo de Galvão Bueno faz uma digressão para poder introduzir o tom sarcástico quanto às diferenças sociais existentes na cidade, estratégia também recorrente na constituição do estilo da Aerolândia. Isso pode ser conferido em "Eles coalhavam o espelho do Lagamar. Ali, vislumbrei um rio que traz dejetos da área rica e os despeja na pobre sem pedir licença." (AEROLÂNDIA, 2010d). O próprio sujeito percebe tal digressão, pois, para retornar ao estilo forjado, aciona o termo "Voltando", no parágrafo seguinte.

Por fim, é válido salientar também outro recurso recorrente no estilo da publicação, uma vez que realiza a escolha do sujeito do discurso. Trata-se do uso de termos que remetem a traços característicos da cidade, em conformidade com o universo que a Aerolândia busca ressaltar acerca de Fortaleza. Certos efeitos de sentido são alcançados, desse modo, com o uso de termos como "Cajuzinho", para remeter às moças bonitas da periferia, e "negrada", para o grupo de pessoas que leem a publicação. 


\section{Considerações finais}

No presente artigo, buscou-se construir uma noção discursiva de estilo, baseada, por um lado, na polêmica como interincompreensão e, por outro, na ideia de que o estilo é decorrência das escolhas realizadas pelos sujeitos do discurso.

Para isso, tomou-se como base Possenti (2008), que trabalha com a noção de repertório e de que todo enunciado tem estilo, uma vez que é resultado das opções do sujeito, que associa uma forma a um conteúdo, o que já seria por si do âmbito estilístico; Discini (2009), defensora da existência de duas dimensões para o estilo, a da totalidade (homogênea) e a da individualidade (heterogênea); Maingueneau (1983, 1984), que contribui com a ideia de polêmica como interincompreensão, afirmando que a constituição do discurso Mesmo se dá por meio da elaboração do simulacro do Outro, fundada na ausência de compreensão mútua entre os discursos presentes na relação.

Assim, propôs-se que a construção do simulacro do Outro e da apresentação do eu teriam como materialidade as escolhas resultantes da associação entre forma e conteúdo, e tais escolhas, por sua vez, trariam como consequência a apreensão do estilo em dois níveis: o da totalidade, que demonstraria a homogeneidade estilística de um discurso, e o da individualidade, que flagraria os aspectos individuais de cada enunciado desse discurso, mostrando sua heterogeneidade (ambas as dimensões vistas como válidas para a análise, nesta pesquisa). Para isso, foram enfocadas a ironia, a refutação e a paródia como estratégias linguístico-discursivas.

Com a análise da revista Aerolândia, notou-se ter ela como Outro certo universo de sentidos, valores sócio-ideológicos compreendidos como elitistas, pedantes e excludentes, simbolizados, principalmente, pela revista Aldeota, o que acabou por definir várias de suas escolhas ao relacionar forma e conteúdo. Com isso, criou-se um sujeito representativo de um estilo que, mesmo se apresentando como crítico, é descentrado, descomprometido e não assume para si responsabilidades sobre o dito. Prova disso é o uso de personagens nos editoriais e de pseudônimos nos textos que compõem a publicação.

Percebeu-se ainda a opção por um senso de humor relacionado às regiões mais periféricas da cidade e que não se exime de colocar a si próprio como objeto de chacota. A escolha de termos que remetem a esse universo de sentidos e o uso de elaborações sarcásticas para se referir ao desnível social presente em Fortaleza, além das menções irreverentes ao sexo são outros bons exemplos de como a relação forma e conteúdo atuou na constituição do estilo da Aerolândia, no que concerne à sua totalidade.

Para concluir, quanto à unidade, os aspectos estilísticos mais relevantes em cada texto foram mostrados no tópico referente à análise e, conforme se havia 
hipotetizado, viu-se que a consideração da individualidade de estilo de cada enunciado pode, sim, ser operacional e não invalida a análise da totalidade.

FARIAS, O. M. de. Style in discursive perspective: an analysis of Aerolândia magazine. Alfa, São Paulo, v.57, n.1, p.53-79, 2013.

- ABSTRACT: In this work, we aim at developing a notion of style from a discursive perspective, using the Discourse Analysis' theoretical outline, according to the French approach. Possenti (2008), who works with the notion of repertoire and with the idea that every statement has style; Discini (2009), who defends the existence of two dimensions of style: totality (homogeneous) and individuality (heterogeneous); and Maingueneau (1983, 1984), who contributes with the idea of polemics as inter-incomprehension, were referenced. The first four Aerolândia magazine's editorials were analyzed, and we could verify that its Other is mainly the magazine, which ended up defining several of its choices when relating form and content, and, consequently, it was a fundamental element in elaborating the publication style. We also noticed the choice for a sense of humor related to the city's most peripheral areas, and a choice of terms that points to that universe of senses. Additionally, we verified that, as thought in the hypothesis, style individuality consideration in each statement could be scientifically productive and doesn't invalidate the analysis of totality.

- KEYWORDS: Style. Discourse. Discursive polemics.

\section{REFERÊNCIAS}

AEROLÂNDIA. Fortaleza: Calaméo, n.1, 8 abr. 2010a. Disponível em: < http:// pt.calameo.com/read/00023924299bce6c098a9>. Acesso em: 25 jun. 2011.

AEROLÂNDIA. Fortaleza: Calaméo, n.2, 15 abr. 2010b. Disponível em: < http:// pt.calameo.com/read/000239242ec11934e55c2>. Acesso em: 25 jun. 2011.

AEROLÂNDIA. Fortaleza: Calaméo, n.3, 22 abr. 2010c. Disponível em: < http:// pt.calameo.com/read/0002392423136934891b9 >. Acesso em: 25 jun. 2011.

AEROLÂNDIA. Fortaleza: Calaméo, n.4, 29 abr. 2010d. Disponível em: < http:// pt.calameo.com/read/00023924206f596d0a7a0 >. Acesso em: 25 jun. 2011.

ALDEOTA. Fortaleza: Calaméo, n.1, 20 fev. 2010a. Disponível em: < http:// pt.calameo.com/read/0002067473333fded11a6>. Acesso em: 25 jun. 2011.

ALDEOTA. Fortaleza: Calaméo, n.2, 27 fev. 2010b. Disponível em: < http:// pt.calameo.com/read/00020674779e8c487f134>. Acesso em: 25 jun. 2011.

ALDEOTA. Fortaleza: Calaméo, n.3, 06 mar. 2010c. Disponível em: < http:// pt.calameo.com/read/0002067472a1486b2803a>. Acesso em: 25 jun. 2011.

ALDEOTA. Fortaleza: Calaméo, n.4, 13 mar. 2010d. Disponível em: < http:// pt.calameo.com/read/00020674705aaf39de097>. Acesso em: 25 jun. 2011. 
AUERBACH. E. Mimesis. São Paulo: Perspectiva, 1971.

BAKHTIN, M. Problemas da poética de Dostoiévski. Rio de Janeiro: ForenseUniversitária, 1981.

BALLY, C. Traité de stylistique fraiçaise. 3.ed. Paris: Librairie C. Klincksieck, 1951.

BRAIT, B. Ironia em perspectiva polifônica. Campinas: Ed. da UNICAMP, 1996.

BRANDÃO, H. N. Subjetividade, argumentação, polifonia: a propaganda da Petrobrás. São Paulo: Ed. da UNESP, 1998.

BÜHLER, K. Teoría del langage. Madri: Revista de Occidente, 1950.

CÂMARA JUNIOR, J. M. Contribuição à estilística da língua portuguesa. Rio de Janeiro: Simões, 1953.

DISCINI, N. O estilo nos textos. 2.ed. São Paulo: Contexto, 2009.

DUCROT, O. O dizer e o dito. Campinas: Pontes, 1987.

DUCROT, O.; BARBAULT, M. C. O papel da negação na linguagem comum. In: DUCROT, O. Provar e dizer. leis lógicas e leis argumentativas. São Paulo: Parma, 1981. p.93-104.

FARIAS, O. M. de. A polêmica como interincompreensão em artigos de opinião acerca do Estatuto da Igualdade Racial. 2008. 167f. Dissertação (Mestrado em Linguística) - Faculdade de Letras, Universidade Federal do Ceará, Fortaleza, 2008.

FISHMAN, Y. Sociologia del lenguage. Madri: Ediciones Cátedra, 1979.

GRANGER, G. Filosofia do estilo. São Paulo: Perspectiva: EDUSP, 1968.

GUMPERZ, G. G. The Speech Community. In: GIGLIOLI, P. P. (Org.). Language and Social Context. Middlesex: Penguin, 1968. p.71-114.

HYMES, D. On communicative competence. In: PRIDE, J. B.; HOLMES, J. (Org.). Sociolinguistics. Harmondsworth: Penguin Books, 1972. p.269-293.

LABOV,W. Le dégagement dês styles contextuels. In: LABOV,W. Sociolinguistique. Paris: Éditions de Minuit, 1973. p.231-255.

LAVANDERA, B. R. Variación y significado. Buenos Aires: Hachette, 1984.

MAInGUENEAU, D. Gênese dos discursos. Tradução de Sírio Possenti. Curitiba: Criar, 1984.

Semantique de la polemique: discours religieux et ruptures ideologiques au XVIIe siècle. Lausanne: L'Age d'Homme, 1983.

ORLANDI, E. Destruição e construção do sentido: um estudo da ironia. In: COLÓOUIO DO DEPARTAMENTO DE LINGÜÍSTICA DO IEL, 1983, Campinas. Anais... Campinas: UNICAMP, 1983. p.66-97. 
PEREIRA, M. H. de M. Tinha um gênero no meio do caminho: a relevância do gênero para a constituição do estilo em textos escolares. 2005. 276f. Tese (Doutorado em Linguística Aplicada) - Instituto de Estudos da Linguagem, Universidade Estadual de Campinas, 2005.

POSSENTI, S. Discurso, estilo e subjetividade. 3.ed. São Paulo: Martins Fontes, 2008.

SANT'ANNA, A. R. Paródia, paráfrase e cia. São Paulo: Ática, 1985.

SPITZER, L. Lingüística y história literária. Madrid: Gredos, 1974.

Recebido em 30 de setembro de 2011

Aprovado em 24 de novembro de 2012 
